\title{
Psicanálise Crítica: A Escuta do Sofrimento Psíquico e suas Implicações Sociopolíticas
}

\author{
Priscila Melo Ribeiro Lima ${ }^{1}$ \\ ${ }^{1}$ Universidade Federal de Goiás, GO, Brasil.
}

\author{
Sostenes Cezar de Lima ${ }^{1}$ \\ ${ }^{1}$ Universidade Estadual de Goiás, GO, Brasil.
}

Resumo: O processo de constituição psíquica é perpassado por discursos identificantes que modelam a imagem de si. Esse psiquismo é formado dentro de uma família pertencente a determinado grupo social. A partir da análise do conceito freudiano de mal-estar e do contrato narcísico de Aulagnier, investigamos as lógicas estabelecidas entre o sujeito e a conjuntura social. O reinvestimento narcísico pós-Édipo se pauta no Ideal-de-Eu construído a partir das interdições e dos ideais parentais e socioculturais. Discursos identificatórios hegemônicos, que ressaltam a normatividade nas identidades sexuais, de gênero, étnicas e etárias, constroem identificações marcadas pela exclusão. Pensar nos modos de identificação na contemporaneidade implica assumir que os elementos formadores dessa identidade provêm da história de vida e dos processos histórico-sociais. Neste artigo, analisamos o sofrimento sociopsíquico a partir da narrativa de uma participante de um projeto de pesquisa realizado em centro de atendimento psicológico de uma universidade pública. Foram realizadas entrevistas individuais, cuja escuta clínica nos propiciou compreender as implicações sociais e políticas do sofrimento psíquico do sujeito em desamparo social. Para tanto, nos apoiamos em conceitos da psicanálise e da análise do discurso crítica para a análise das entrevistas. Observamos que o processo de exclusão social escancara o engodo do pacto social no qual o sujeito é desinvestido e lançado no desamparo. Nesse contexto, a experiência narrada e a escuta analítica crítica podem se estabelecer como estratégias de resistência ante a exclusão social.

Palavras-chave: Psicanálise crítica, Narrativas de Vida, Discurso Hegemônico, Discurso de Resistência, Contrato Narcísico.

\section{Critical Psychoanalysis: Psychic Suffering Listening and its Socio-political Implications}

\begin{abstract}
The psyche constitution is permeated by identifying discourses that shape the image of itself. This psyche is constituted within a family belonging to a specific social group. By analyzing the Freudian concept of malaise and Aulagnier's 'narcissistic contract', we investigate the logic between the subject and the social context. The narcissistic reinvestment after Oedipus happens according to the Ideal-of-Ego constructed from the parental and social interdictions, but also following ideational cultural and parental introjection. Hegemonic identificatory discourses that emphasize normativity in sexual, gender, ethnic and age identities construct identities marked by exclusion. Thinking about the modes of identification in contemporaneity implies assuming that the elements that form this identity come from the history of life and social-historical processes. We analyzed the socio-psychic suffering from listening to the narrative of a participant in a research project carried out in a psychological care center of a public university. Individual interviews were conducted whose clinical listening enabled us to understand the social and political implications that constitute the psychic suffering of the subject in social neglect. We rely on concepts of Psychoanalysis and Critical Discourse Analysis
\end{abstract}


that provided us with subsidies for the analysis of interviews. We observe that the process of social exclusion has eluded the deception of the social pact in which the subject is disinvested and cast into helplessness. In this context, narrative experience and critical analytical listening can be established as strategies of resistance to social exclusion.

Keywords: Critic Psychoanalysis, Narratives, Hegemonic Discourse, Resistance Discourse, Narcissistic Contract.

\title{
Psicoanálisis Crítico: la Escucha del Sufrimiento Psíquico y sus Implicaciones Sociopolíticas
}

\begin{abstract}
Resumen: La constitución psíquica es atravesada por discursos identificadores que modelan la imagen de sí. Este psiquismo se constituye dentro de una familia perteneciente a cierto grupo social. A partir del análisis del concepto freudiano del malestar y del "contrato narcisista" de Aulagnier, analizamos las lógicas establecidas entre el sujeto y la coyuntura social. La reinversión narcisista después del Edipo se basa en el Ideal-de-Yo construido a partir de prohibiciones y ideales parentales y socioculturales. Los discursos identificatorios hegemónicos que resaltan la normatividad en las identidades sexuales, de género, étnicas y de edad construyen identificaciones marcadas por la exclusión. Pensar en los modos de identificación en la contemporaneidad implica asumir que los elementos formadores de esa identidad provienen de la historia de vida y de los procesos histórico-sociales. En este artículo, analizamos el sufrimiento sociopsíquico desde la escucha de la narrativa de una participante de un proyecto de investigación realizado en centro de atención psicológica de una universidad pública. Se realizaron entrevistas cuya escucha clínica nos propició comprender las implicaciones sociales y políticas que constituyen el sufrimiento psíquico del sujeto en desamparo social. Apoyamos en conceptos del Psicoanálisis y del Análisis del Discurso Critico para analizar las entrevistas. Observamos que el proceso de exclusión social desvela el engaño del pacto social en el cual el sujeto es desinvestido y lanzado en el desamparo. En ese contexto, la experiencia narrada y la escucha analítica crítica pueden establecerse como estrategias de resistencia ante la exclusión social.
\end{abstract}

Palabras clave: Psicoanálisis crítico; Narrativas de Vida; Discurso Hegemónico; Discurso de Resistencia; Contrato Narcisista.

A escuta clínica do sofrimento psíquico necessita ser também uma escuta do sofrimento social. Sem entrar na dicotomia perpetrada nos diversos espaços de construção da psicologia, compreendemos que escutar o sujeito é escutar seus dramas e suas tramas, social e psiquicamente construídas. A trama psíquica se constrói a partir do que é fornecido socialmente, que, por sua vez, é subjetivamente assimilada. Assim, podemos pensar o sofrimento por meio dos romances familiares e sociais. Partimos do pressuposto de que os discursos sociocultural e parental são determinantes na construção da identidade. A análise que aqui propomos parte primeiramente da busca por compreender de maneira teórica as reverberações psíquicas do contrato narcísico e de seu esgarçamento com base em Freud, Aulagnier e Gaulejac. Em seguida, analisamos a narrativa de uma mulher idosa objetivando compreender as construções psíquicas e sociais presentes em seu sofrimento. Para tanto, nos apoiaremos em alguns conceitos da psicanálise, psicossociologia e análise do discurso.

\section{Contrato narcísico e suas reverberações psíquicas}

Aulagnier (1989), em estudo sobre o discurso identificante, ressalta a importância do conhecimento que emerge a partir da escuta via transferência. 
É um conhecimento, "não sobre O Desejo, O Tempo, A Realidade, mas sobre a singularidade de sua própria história libidinal, de sua própria relação com o desejo, o passado, o futuro, a realidade" (p. 20). A realidade histórica, pensada a partir das tramas sociais construídas e repassadas ao longo das gerações, faz-se presente nos projeto e discurso parentais. É necessário considerar a importância dessa realidade na organização psíquica do sujeito, pois ela revela "tanto os acontecimentos que atingiram o corpo da criança $\mathrm{e}$ os que foram efetivamente vividos pelos pais, durante a infância da pessoa, quanto os discursos e injunções que lhe foram impostos" (Violante, 2000, p. 66).

O processo de constituição do psiquismo é perpassado por diversos discursos identificantes que constroem a noção de identidade. Esse psiquismo se constitui dentro de uma família pertencente a um grupo de determinada sociedade. Podemos, então, pensar a construção da identidade, sempre ilusória e nunca total, a partir da metáfora apresentada por Freud em "O mal-estar na civilização" (1930/2010). As sucessivas construções identitárias preservam os elos com as identificações anteriores e, assim, em um processo de contínua construção, o sujeito vai agregando e integrando os sucessivos discursos que o apresentam. Esses elos, primeiramente estabelecidos com os pais, se formam também através das figuras de identificação nas outras instituições nas quais o sujeito se insere.

Freud (1914/2010), em "Introdução ao narcisismo", destaca a importância dos ideais culturais na formação do Ideal de eu, herdeiro do Édipo. O reinvestimento narcísico após o Édipo vai acontecer a partir desse ideal, construído a partir das interdições parentais e sociais e introjeção das figuras paterna e materna. Essa passagem marca a entrada do sujeito no circuito simbólico, na alteridade e na vida em sociedade, na qual seu desejo está submetido ao desejo do outro. Há uma substituição do narcisismo primário por um pacto social, a partir do qual o sujeito renuncia seu desejo selvagem de forma a aceder às normas sociais, integrar a sociedade e ter acesso ao simbólico.

$\mathrm{Na}$ busca por compreender a fonte social de sofrimento, Freud (1930/2010) enfatiza a ideia do pacto social sob o qual o indivíduo, ao reprimir seus impulsos agressivos, teria acesso às benesses da horda - principalmente segurança e pertencimento, mas também o sofrimento daí decorrente. Nesse sentido, Freud (1930/2010) ressalta a fonte social do sofrimento, no que concerne à

insuficiência das normas que regulam os vínculos humanos na família, no Estado e na sociedade.... Esta [fonte de sofrimento] não queremos admitir, não podendo compreender por que as instituições por nós mesmos criadas não trariam bem-estar e proteção para todos nós (pp. 43-44).

As normas que regulam os vínculos e a vida libidinal do sujeito requerem a repressão instintual em troca de uma promessa de felicidade a posteriori, baseada no bem-estar e na proteção. Freud (1930/2010) ainda destaca que o eu admite abdicar certas fontes de satisfação libidinal apenas quando tem em vista algo substitutivo. Esse pacto social parte do pressuposto de que formamos uma sociedade, "uma associação na qual cada sócio participa, cedendo um pouco, em nome do bem comum, onde cada um abre mão da satisfação pulsional e, assim, participa da sociedade, da construção de um coletivo", afirma Sequeira (2009, p. 224).

Aulagnier (1979) ressalta o conceito de contrato narcísico ao analisar essas lógicas estabelecidas entre o sujeito e a conjuntura social na qual está inserido. A partir de sua teorização, depreendemos que o investimento narcísico - uma parte do desenvolvimento psicossexual - só é possível se a trama social da qual os sujeitos participam puder lhes investir narcisicamente. Este processo, portanto, confere ao sujeito um lugar de portador de continuidade no conjunto social. O reconhecimento social, em sua vertente positiva, é, desse modo, portador de narcisismo.

Freud (1912/2010), em "Tipos de adoecimento neurótico", ressalta que as raízes do sofrimento psíquico se encontram na história do desenvolvimento da libido e nos fatores nele atuantes, tais como as influências do mundo externo vividas na infância. A frustração é destacada como um entre os diversos fatores que podem levar ao desencadeamento da neurose e consequente sofrimento. Diante da retirada de um objeto real do mundo exterior desejado e investido pelo sujeito, o eu vai em busca de um objeto substitutivo. A frustração surge quando não há a substituição do objeto perdido. Como consequência, há um aumento da tensão psíquica. No entanto, o eu muitas vezes não consegue sequer buscar um novo objeto de investimento e descarga. Uma segunda causa de sofrimento decorreria da 
tentativa do sujeito em se adequar à realidade e cumprir suas exigências. Ao perseguir essa adequação, esse sujeito, afirma Freud, se depara com insuperáveis dificuldades internas:

No primeiro tipo sobressai uma mudança no mundo externo, no segundo a tônica recai sobre uma mudança interna. . . . No segundo caso, existe de antemão o conflito entre o esforço de permanecer como é e o de mudar conforme novos intuitos e novas exigências da realidade.... O adoecimento por frustração pode também ser visto como incapacidade para adequação à realidade, no caso, isto é, em que a realidade frustra a satisfação da libido. $\mathrm{O}$ adoecimento nas condições do segundo tipo leva a um caso especial de frustração. . . . Em virtude do conflito que logo aparece no segundo tipo, as duas espécies de satisfação, a habitual e a desejada, são igualmente inibidas (Freud, 1912/2010, pp. 233-235).

As exigências de satisfação do mundo externo e de mudança do mundo interno, apesar de serem destacadas por Freud separadamente, são intrínsecas. Ao final do artigo, ele destaca que essa oposição é infecunda, já que a situação psíquica abrange ambas. Gaulejac (2014), em discussão sobre as raízes sociais da neurose, destaca que essa frustração, proveniente tanto da impossibilidade de encontrar novo objeto de investimento quanto da impossibilidade do sujeito em se adequar, pode ser compreendida mediante discurso social. O sofrimento desencadeado pela frustração pode surgir também quando o discurso social desvaloriza e desautoriza as figuras de identificação desse sujeito. A desvalorização narcísica é assim sentida quando a imagem que os outros refletem é uma imagem negativa. $\mathrm{O}$ eu é desse modo, atacado em sua imagem e seus objetos de identificação são retirados.

Como consequência, ocorre um déficit narcísico forjado gradativamente através de ataques cumulativos ao eu do sujeito. O acúmulo do reconhecimento pautado na negatividade rompe ou esgarça o contrato narcísico gerando sofrimento. Esse esgarçamento pode surgir como resultado de dois tipos de violência, segundo Carreteiro (2003): a) violências explícitas que marcam principalmente o corpo; e b) humilhações implícitas mais sutis, que deixam traços sem marcar o corpo. O corpo, com suas marcas da diferença, e os discursos e injunções que impõem ao sujeito um lugar de exclusão e de esgarçamento do investimento narcísico, são portadores de sofrimento.

\section{Identificação e contrato narcísico}

Em seu estudo sobre as neuroses de classe, Gaulejac (2014) ressalta que, se considerarmos que o destino de um indivíduo é determinado pela sua história, não podemos reduzi-la apenas à história de suas relações afetivas familiares. As relações familiares são portadoras de aspectos afetivos, ideológicos, culturais e socioeconômicos. Não podemos negar a história social como elemento constituinte dos destinos pessoais. Essa perspectiva se aproxima da impossibilidade, destacada por Aulagnier (1979), de se analisar o eu desconsiderando os campos social e cultural de pertença do sujeito. É nesses campos que o projeto parental, que reflete o narcisismo dos pais, se constrói.

Ao destacar o projeto parental como um desses componentes do romance familiar, Gaulejac (2014) ressalta a importância de se considerar o projeto social como sua parte integrante. Tanto os encadeamentos do desejo presentes na relação entre os pais e seus filhos quanto o projeto social possuem aspirações e desejos que remetem aos desejos inconscientes dos pais e às aspirações condicionadas pelo contexto social. A partir disso, Gaulejac une o projeto parental ao projeto social e os reintegra em quatro níveis de análise: a) um nível inconsciente que remete ao narcisismo primário e ao Ideal-de-Eu; b) um nível afetivo que conduz o sujeito a se desenvolver pela identificação com aqueles que correspondem ao modelo idealizado internalizado; c) um nível ideológico que leva o sujeito a retomar por sua própria conta os valores, normas e ethos de seus modelos de identificação e a rejeitar os que lhe são apresentados como o avesso desses modelos; e d) um nível sociológico, pois cada modelo de identificação traz consigo ideais coletivos, modelos de sucesso social que se traduzem em práticas religiosas, políticas e sociais, das quais a criança é levada a participar.

O projeto parental, principal força motriz das instâncias ideais do Super-Eu, é herdeiro dos projetos das gerações anteriores, do grupo familiar que o construiu. Apesar de sua constante reatualização histórica, ele é a expressão dos projetos construídos ao longo da história social da família. Logo, todo projeto parental internalizado se ajusta às demandas inconscientes dos pais e às condições sociais de existência com as quais os pais são confrontados em suas próprias vidas. 
Aulagnier $(1979,1989)$ destaca a fundamental contribuição dos significados partilhados no meio social para os processos de identificação do bebê: a resposta materna ante demanda primária do bebê tem uma função identificatória - a identificação primária; a imagem do corpo da criança esperada compõe o que Aulagnier (1999) chama de eu antecipado, ao qual é dirigido o discurso materno. Assim, a imagem corporal do eu carrega a marca do desejo materno. Esse eu é historiado e se insere em uma ordem simbólica e temporal dentro de um sistema de parentesco.

Em seguida, ocorre a identificação especular na qual o Eu-ideal, identificado com a resposta ao suposto desejo materno, se forma. Essa identificação especular que ocorre no registro imaginário só é possível devido à associação que o bebê faz entre a imagem refletida no olhar materno com o "discurso proferido pela mãe ou pelos pais ao filho, sobre o filho e pelo filho", destaca Violante (2000, p. 67). No registro do imaginário, a emergência jubilosa de si está sujeita ao entrelaçamento da imagem especular sancionada pelo olhar materno e o enunciado identificatório dirigido à criança pela mãe. Ou seja, ocorre uma amarração entre o visto e o escutado, enfatiza Aulagnier (1979).

Nessa relação dual do início da vida, o bebê está submetido ao desejo materno. Sem a presença materna para suprir sua imaginária onipotência, o infans é apenas uma falta, pois ainda não está inserido na rede simbólica. A busca constante pelo olhar de desejo da mãe é fundamental para que o bebê se arrisque a ir em direção ao outro e experimentar sua capacidade de individuação, afirma Gaulejac (2006). Essa significação primária, que antecede a aquisição do signo linguístico, é atribuída às palavras da mãe que se estabelecem como base para a aquisição da linguagem. Violante (2000) destaca que

com o advento do $\mathrm{Eu}$, a aquisição da linguagem vem submeter o arbítrio (seja benéfico ou maléfico) da palavra materna à convenção sociocultural ditada pelo signo linguístico, graças ao qual as palavras são descobertas como portadoras de significados partilhados pelo meio social e independentes do desejo materno (p. 68).

Ao passar do narcisismo primário, a criança busca no discurso social a confirmação da palavra materna e o investimento narcísico perdido. $\mathrm{O}$ eu é historicizado e estruturado pela linguagem a partir dos discursos parentais e do discurso social. A imagem projetada no olhar materno é buscada nos olhares dos outros. O eu, para Aulagnier (1990b), seria um compromisso identificatório que permite ao sujeito reconhecer-se como elemento de um conjunto, mas também como ser singular, "como efeito de uma história que de longe [o] precedeu e como autor daquela que [sua] vida conta" (p. 187). Nessa perspectiva, se destacam dois princípios do funcionamento identificatório - a permanência e a mudança. A identidade do indivíduo, resultado da permanência de certos traços, é construída, portanto, a partir dos processos identificatórios que formam a trama da sua biografia pautada na palavra parental, em conjunto com os elementos comuns a sua família, sua classe de pertencimento e ao seu meio.

Entretanto, o eu, reafirma Aulagnier (1989), é também historiador e não se resume a ser apenas um efeito daqueles discursos. Nesse sentido, Gaulejac (2014) ressalta a capacidade do eu em intervir na própria história e reformulá-la de acordo com seu desejo e discurso do meio, e, assim, com a cultura. O eu é compreendido como constituído pelo discurso social, mediatizado por um meio psíquico organizado pelo desejo e discurso dos pais. Para tanto, o eu, para ao se constituir, "exige realidade: prazer real, significação e reconhecimento advindo de pelo menos um outro Eu que lhe sirva de ponto de apoio, modelo identificatório e suporte de investimento" (Violante, 2000, p. 69). Quando da constituição do Ideal-de-Eu, o eu necessita encontrar na realidade social a promessa de que seus ideais são pelo menos parcialmente tangíveis, reconhecidos e valorizados. Esses ideais são objetos de demanda identificatória e o eu necessita se projetar em uma imagem identificatória investida e reconhecida socialmente.

É nesse sentido que Aulagnier (1979) ressalta a importância do contrato narcísico e o consequente sofrimento desencadeado quando esse contrato é feito pela via do negativo. Por essa via, o eu é anunciado como portador da vergonha ao invés de ser reconhecido e investido. Compreendemos que existe nessa forma de sofrimento psíquico o que Freud articulou como sendo uma fonte social do sofrimento. Ele destaca a incapacidade das instituições sociais de cumprirem com sua parte no contrato social de garantir o bem-estar e a proteção do eu. Esse acordo entre o indivíduo e seu grupo foi fundante para o nascimento da civilização - a "substituição do poder 
do indivíduo pelo da comunidade é o passo cultural definitivo. Sua essência está em que os membros da comunidade se limitam quanto as possibilidades de gratificação" (Freud, 1930/2010, p. 56). A contraparte da sociedade seria o reconhecimento do indivíduo enquanto "vizinho, colaborador, como objeto sexual de um outro, como membro de uma família e de um Estado" (Freud, 1930/2010, p. 55).

O processo de exclusão social escancara o engodo desse pacto social no qual certos sujeitos são muitas vezes desinvestidos e lançados no desamparo sem possibilidades de contorná-lo. É a falência do contrato narcísico. Freud (1930/2010) ressalta que essa fonte de sofrimento - "a insuficiência das normas que regulam os vínculos humanos na família, no Estado e na sociedade" (p. 43) - é, por nós, negada. Ele afirma que, embora não queiramos admitir, não compreendemos "por que as instituições por nós mesmos criadas não trariam bem-estar e proteção para todos nós" (Freud, 1930/2010, p. 44). Diante disso, imputamos ao sujeito excluído a culpa por sua infelicidade.

O sofrimento surge quando seus processos identitários são perturbados ao não ser reconhecido socialmente, deixando o sujeito em extrema confusão entre o que é o olhar dos outros e para si mesmo. Isso ocorre porque a construção da identidade se dá através das sucessivas identificações com as imagos paterna e materna e identificações com os aspectos e atributos sociais dos personagens sociais tomados como suportes desse processo. Dentre esses suportes, podemos destacar as relações intrafamiliares, as relações sociais e a posição social ocupada pelo sujeito.

A leitura freudiana dos processos identificatórios nos leva a compreender que o sujeito buscará figuras substitutas às figuras parentais. Ao se identificar com um ideal, com uma autoridade, com as instituições e seus discursos, esse sujeito busca também a confirmação do discurso parental que alimentava seu narcisismo. As palavras pronunciadas pelo meio social, "pelo grupo social investido pela criança, passam a adquirir o atributo de emblemas identificatórios", ressalta Violante (2000, p. 68). Quando da submissão da palavra materna ao arbítrio da convenção sociocultural a partir da aquisição da linguagem e inserção nos grupos sociais mais amplos, a criança descobre as palavras como portadoras de significados partilhados pelo meio social e independentes do desejo materno. Assim, "homem" passa a significar poder; "mulher", fraqueza, "cabelo liso" significa cabelo bonito; "negro" e "preto", palavras negativas.

São essas discrepâncias que fazem emergir o sofrimento e que se evidenciam nas narrativas construídas pelo eu em suas formas de lidar com sua própria identidade. Estudos de Davis (2016), Domingues e Rosa (2014), Fanon (1952), Musatti-Braga (2015), Musatti-Braga e Rosa (2018), Rosa (2002, 2012), Rosa e Mountian (2013) e Souza (1983) ressaltam as reverberações dos ideais culturais, presentes nos discursos hegemônicos, tanto na construção identitária quanto na produção de sofrimento psíquico e social de pessoas socialmente excluídas. Gonçalves Filho (1998), em pesquisa com mulheres vítimas de humilhações sociais, destaca a angústia que toma conta dos corpos, gestos, imaginação e voz do sujeito humilhado.

Violante (2000) teoriza, a partir da perversidade da exclusão social, sobre a potencialidade melancólica observada nos sujeitos socialmente excluídos. Seu corpus de pesquisa foi composto por narrativas de crianças e jovens em situação de vulnerabilidade social e em conflito com a lei. Foram observadas nas narrativas diversas características da melancolia "adulta", tais como baixa autoestima, baixo investimento da libido objetal, negação da frustração e de todo sentimento hostil, demanda de amor e de identificação endereçada ao outro idealizado, demanda dirigida a si mesmo de ser conforme a oferta do outro, dependência de provisões narcísicas vindas de fora, agressividade mais voltada para si mesmo e sexualidade difusa.

Nas pesquisas e estudos citados, os sujeitos entrevistados e observados eram vítimas de humilhação social e de um rompimento do contrato narcísico. Todos os sujeitos apresentavam um sofrimento psíquico e social, e uma identificação endereçada à idealização do modelo socialmente construído e pautada em um discurso que anula quem dele destoa. Fanon (1952) e Souza (1983) ressaltam, por exemplo, como pessoas negras acabam por adotar um Ideal-de-Eu pautado nos ideais brancos, processo denominado de branqueamento da identidade. Gaulejac (2014), em oficinas grupais, ressalta também como sujeitos imigrantes e em situação de vulnerabilidade social possuem como elemento-chave identitário a vergonha por não se enquadrarem no discurso hegemônico.

Toda história pessoal é marcada por conflitos da história familiar; mas toda história familiar é atravessada pelas contradições da história social; e toda 
história é uma história das relações entre as classes sociais (Gaulejac, 2014). Os conflitos do sujeito estão, portanto, amarrados às contradições que caracterizam a história de seu grupo de pertencimento e ao campo social, nos quais seus processos identificatórios se ancoram. Podemos afirmar então a importância da análise da gênese social na composição dos conflitos psicológicos.

Carreteiro (2003), ao analisar algumas formas de sofrimentos sociais, focaliza certas dimensões, como a humilhação, a vergonha e a falta de reconhecimento vividas por categorias subalternizadas e os efeitos produzidos nas dimensões comunitária, social e grupal. Nos grupos subalternizados e silenciados, esse sofrimento não tem visibilidade social, pois se inscreve no interior das subjetividades sem, no entanto, ser compartilhado coletivamente. Isso se dá porque a sociedade dispõe de poucos suportes para auxiliar sua expressão. Assim, o sofrimento é censurado pelo próprio sujeito, imerso no sentimento de vergonha e inadequação.

Esse sofrimento social pode ser visto como decorrente de um sofrimento psíquico, mas é também éticopolítico, oriundo da dor das injustiças sociais que certos sujeitos estão expostos, afirma Carreteiro (2003). Gaulejac (2014) destaca que o sofrimento psíquico emerge quando os conflitos vinculados à trajetória social e ao desenvolvimento psicossexual se escoram mutuamente e produzem um reforço recíproco. No entanto, são os integrantes de categorias sociais mais subalternizadas os que vivenciam acentuadamente situações que os desvalorizam, humilham, fazendo-os se sentirem envergonhados. Esses sujeitos participam de dinâmicas sociais, segundo Carreteiro (2003) e Gaulejac (2014), que lhes depreciam o corpo e invalidam a importância dos seus códigos sociais e culturais, além de desqualificar suas experiências vividas. Tais lógicas almejam não somente submeter os corpos através da violência real e simbólica, buscando criar indivíduos dóceis, como analisa Foucault (1976/1988), ou homogeneizá-los de forma a silenciar qualquer possibilidade de resistência. Esses autores sustentam que essas lógicas se apropriam do mais profundo das subjetividades e levam os sujeitos a se simbolizarem como inadequados, como "normais inúteis" à sociedade (Carreteiro, 2003, p. 60).

Nesse sentido, Carreteiro (2003) destaca o surgimento de dois imaginários prevalentes que moldam as identidades. $\mathrm{O}$ primeiro seria o imaginário da excelência que engloba o ideário da perfeição e da superação de si mesmo, que é permeado por valores de inserção, carreira, poder e qualificação social, mobilidade e fluidez. Essa lógica da excelência homogeneíza as vivências e atinge todas as esferas da vida social. Tal qual na sociedade disciplinar descrita por Foucault (1988), podemos falar de uma docilidade dos corpos submetidos ao imaginário da perfeição das formas, saúde, alimentação, sexualidade. Existe um imperativo sobre o que se deve comer, como deve ser a vida sexualmente saudável e aceitável, o que vestir, como se exercitar etc. O imperativo da produtividade, da eficiência e da qualidade total alienam o sujeito em sua busca por ascensão e prestígio social. Não apenas isso. Existe um corpo ideal e socialmente valorizado - um corpo cujas feições e formato são desejados branco, macho, heterossexual, produtivo, magro.

Esse imaginário da excelência desencadeia $o$ imaginário da inutilidade. Esse segundo imaginário se pauta nos valores de fracasso, falta de inserção, estagnação, desqualificação e vergonha. Carreteiro (2003), a partir da análise de Castel \& Haroche (2001), afirma que os indivíduos que vivem nesse imaginário têm poucos suportes objetivos, sociais e familiares, além de pouca chance de desenvolverem estratégias individuais de resistência e modificação de suas condições. Esses autores sustentam que, para os indivíduos que vivem sob a égide do imaginário da inutilidade, "ser um indivíduo nem sempre é conotado positivamente.... experimentam um processo de desfiliação social" (Carreteiro, 2003, p. 59). Consequentemente, são sujeitos com maiores possibilidades de experimentar algum tipo de sofrimento social, que "deixa marcas psíquicas com pouca ou nenhuma visibilidade social” (p. 59); são "indivíduos por falta” (p. 121).

Os indivíduos por falta são calados, apagados, afastados. Gaulejac (2006) afirma que isso acontece porque esses indivíduos provocam repulsa nos demais sujeitos. A miséria, assim como outras situações sociais como a loucura e a velhice, parece encarnar tudo o que a sociedade moderna abomina: impossibilidade de consumo, decrepitude e morte. Gaulejac ressalta que essas condições sociais são interpretadas pela sociedade como sendo consequência de um problema moral - inércia, conformismo, preguiça. Há uma desconfiança em relação ao sujeito miserável. Cria-se o imaginário de que não se pode confiar em alguém que deliberadamente não cuida de si e se acomoda à miséria. O sujeito em sofrimento social, 
na verdade, é rejeitado porque denuncia a falha da sociedade em cuidar de seus membros. São eles que denunciam a perversidade do contrato narcísico.

Ante isso, a escuta psicanalítica tem se constituído, desde Freud, como ato de transgressão em relação aos fundamentos da organização social, nos afirmam Rosa e Mountian (2013). Essa escuta precisa se construir enquanto um discurso de resistência ante o discurso social hegemônico, no tocante ao sofrimento. Assim, a psicanálise pode possibilitar o resgate do sujeito de um lugar de silenciamento e convocá-lo a construir novos modos de escrita de si. A experiência narrada e escutada pode se estabelecer como estratégia de resistência ante as situações de humilhação, mas também como modo de identificação.

\section{Percurso metodológico}

A narrativa analisada neste artigo é decorrente de um projeto de extensão e pesquisa realizado em um centro de atendimento psicológico, público e gratuito, de uma universidade pública. A pesquisa foi submetida e aprovada pelo Comitê de Ética em Pesquisa, via Plataforma Brasil. A condução das entrevistas individuais e dos encontros em grupo foi feita pela pesquisadora, e a análise dos dados e construção teórica foram feitas por ambos os pesquisadores. O projeto abrangeu a escuta clínica de idosas socialmente excluídas que, após atendimentos individuais, foram encaminhadas para atendimentos grupais. Os dados pessoais foram alterados de forma a preservar o sigilo e confidencialidade da entrevista. As entrevistas foram gravadas e depois transcritas com a autorização expressa das participantes.

O projeto foi desenvolvido com mulheres idosas voluntárias que se dispuseram a participar das oficinas a partir da divulgação feita em postos de saúde e instituições destinadas ao acolhimento de idosos. Os sujeitos interessados telefonaram para um número disponibilizado nos cartazes de divulgação e, junto com a pesquisadora, agendaram uma entrevista. Foram recebidos quinze telefonemas de idosas interessadas em participar do projeto. Desses quinze, apenas sete mulheres compareceram à entrevista individual agendada. As entrevistas aconteceram em um centro de atendimento psicológico vinculada a uma universidade pública brasileira. A execução do projeto inicialmente abrangeu a escuta dessas sete mulheres idosas que, após entrevistas individuais, foram convidadas a participar de alguns encontros em grupo.
Esses encontros objetivaram o compartilhamento das histórias de vida entre as participantes. Cada encontro, de um total de dez, teve temáticas específicas que abrangeram as rememorações da infância, adolescência, vida adulta, velhice, sexualidade, relacionamentos familiares e morte. Das sete idosas entrevistadas inicialmente, apenas cinco aceitaram participar do grupo. A análise que propomos aqui envolve apenas a fase das entrevistas individuais, haja vista o volume de dados gerados a partir dos encontros grupais. Além disso, essa escolha se deu devido à intenção de nos aprofundarmos nas questões identitárias que envolvem o contrato narcísico e os ideais culturais.

As narrativas individuais foram geradas a partir de entrevistas individuais de acordo com a metodologia "narrativa de vida" proposta de Bertaux (2010). Esse modelo de entrevista aberta tem como objetivo escutar a voz do sujeito. Ou seja, buscamos promover um espaço de escuta em que o sujeito pudesse livremente expor, por meio da narrativa de vida, aspectos discursivos e identitários relativos à sua condição de exclusão e subalternização social. Foram realizadas de uma a duas entrevistas narrativas com cada participante voluntária. Cada narrativa é composta de duas partes: na primeira, a entrevistadora/pesquisadora encorajou a participante a contar sobre sua vida. O sujeito foi estimulado a se apropriar da entrevista de forma que assumisse o papel de narrador. Assim, a atitude da pesquisadora foi demonstrar interesse real pelo que ela narra e evitar interrompê-la. A segunda parte da entrevista se iniciou quando a entrevistada deu sinais claros de que encerrou sua narrativa. A entrevistadora, então, estimulou a entrevistada a voltar a pontos não abordados ou que necessitassem ser mais desenvolvidos (Bertaux, 2010; Flick, 1995/2009; Jovchelovitch \& Bauer, 2002).

Apresentaremos alguns excertos da narrativa de Ivone seguidos de análises e considerações a partir das teorias apresentadas. Na análise da narrativa, focalizamos a análise do discurso da idosa e a forma como as instâncias ideais se manifestaram na narrativa. Assumimos os seguintes objetivos: identificar e analisar como os discursos sociais hegemônicos se fazem presentes no discurso da idosa; analisar a manifestação de aspectos afetivos que evidenciam o sofrimento psíquico-social, como: a) sentimento de culpa; b) sentimento de inferioridade; c) dificuldade diante do complexo de Édipo e suas figuras de identificação; e d) isolamento e fechamento sobre si. 


\section{O caso Ivone - narrativa e discussões}

Dona Ivone, 64 anos, se apresentou de forma tímida e inibida. Demonstrou muita dificuldade em iniciar seu relato e dar continuidade à história $\mathrm{e}$ às lembranças que relatava. Por diversas vezes, foi necessário que a pesquisadora interviesse e fizesse perguntas um pouco mais diretivas como: "Me fale mais sobre sua infância", ou "Me conte mais sobre seu pai/sua mãe/seu marido". Não podemos falar que de fato ocorreu uma relação transferencial entre a idosa e a pesquisadora, haja vista que o encontro aconteceu uma única vez. Mas, no decorrer do encontro, Ivone foi aos poucos se abrindo e se permitindo entrar em contato com sua história e suas memórias. O desejo de escuta e de reconhecimento de si e de sua dor permeou todo o seu relato. Entretanto, esse desejo não foi o suficiente para que um vínculo transferencial se iniciasse - Ivone compareceu à primeira entrevista, mas desistiu de continuar participando do projeto ${ }^{1}$.

Ivone viveu sua infância e adolescência na zona rural. Aos 14 anos, se mudou para a cidade e começou a trabalhar "nas casas dos outros" como empregada doméstica, lavadeira e passadeira de roupas. Ela conta: " minha história de vida, se eu for contar, minha filha, você vai mandar fazer uma novela". Foi uma trajetória marcada pela extrema pobreza e humilhação social. Ivone desabafa:

fui criada sem mãe, só com meu pai morando na fazenda, a gente passou por muita coisa. E graças a Deus não aconteceu nada de grave, porque Deus é muito bom. Porque era. . . hoje a gente já lembra como era e como aconteceu coisas absurdas. Nossa Senhora, jamais uma pessoa daria conta de viver numa situação em que fui criada, né?

Muitas dessas "coisas absurdas", entretanto, Ivone não conseguiu nos contar. Sua narrativa se deu de forma truncada, com muitos momentos de clara angústia e sofrimento ao se relembrar do passado.

Viveu uma infância pobre e com a ausência de sua mãe que morreu quando Ivone era ainda muito nova. Ela "passou por muita coisa". Apesar disso, suas lembranças da infância "na roça" são permeadas de momentos de liberdade e alegria, como observado na sua fala. A lembrança da liberdade da infância se contrasta com as exigências de uma vida na zona rural e necessidade premente de ajudar nas tarefas cotidianas:

Pegava vaca parida de bezerro novo no pasto, sabe? Tipo peão mesmo sabe? Socava arroz na mão pra alimentar os peão na roça quando meu pai tocava roça. E na escolinha que a gente estudou, andava três léguas, uma légua e meia pra ir e outra légua e meia pra voltar. Aí quando chegava à noite tinha que socar arroz pra deixar com uma irmã minha pra cozinhar pros peão e pra nós leva, porque nós fazia nosso almoço lá [na escola].

Seus estudos foram interrompidos quando seu pai decidiu abandonar a vida no campo. Seu sofrimento social emerge a partir dessa mudança. De um lugar de enraizamento da história familiar como era a "roça", Ivone precisou enfrentar o desconhecido e o desenraizamento social. Além disso, enfrentou a violência familiar. Ela desabafa em meio ao choro:

Mudei da fazenda e fomos pra cidade. Aí comecei a trabalhar nas casas dos outros, porque meu pai vendeu... aos poucos ele foi vendendo, foi acabando com tudo, acabou, ou seja, acabou tudo que tinha, né? Aífui trabalhar. Sem... [choro] sem saber fazer nada direito, fui pra casa dos outros trabalhar, aprendendo com toda dificuldade... eu fiz só até o quarto ano, e daí então nunca mais estudei, e é isso aí. Casei com muita dificuldade financeira [choro] .... Meu pai era muito nervoso, muito. Nossa ele era assim, ele bebia um pouco, né? Naquela época, $e$ aí qualquer coisinha ele batia, e nossa, era muito sofrimento [choro], mas eu não guardo mágoa não... eu não gosto muito de ficar falando, porque a gente acaba chorando mesmo [choro]. Mas não tenho mágoa dele não. Eu tive um problema de coração e depois disso eu tô sensivel, qualquer coisinha eu choro, não sei por quê.

É visível a tentativa de racionalizar o choro ante a tantas lembranças doloridas. A culpa por demonstrar fraqueza e por falar de seu pai alcoolista e violento a fazem buscar tentativas de defesa psíquica. Os

\footnotetext{
${ }^{1}$ A desistência de Ivone nos levou a questionar o formato do projeto de extensão (primeiramente individual e posteriormente grupal). Como decorrência disso, estamos em processo de implantação de um serviço de atendimento psicológico, público e gratuito, para sujeitos idosos em situação de vulnerabilidade social.
} 
conflitos de identificação, decorrentes das tensões entre as instâncias ideais, se evidenciam em alguns momentos em que se desculpa e racionaliza o choro. A identificação com as figuras parentais que permeiam a formação do Eu ideal e do Ideal-de-Eu desencadeiam fortes sentimentos de inferioridade e de culpa. Gaulejac (2014) ressalta a anterioridade do sentimento de inferioridade quando, na identificação primária, a criança se percebe irremediavelmente menor que os pais. Diante da constatação real de que a criança não corresponde aos ideais narcísicos paternos que compõem o Eu-ideal, abre-se a ferida narcísica. Ao se mudar para a cidade, Ivone revive constantemente essa ferida ao se deparar com seu lugar social e as atividades laborais que precisa desenvolver. Além disso, com a constatação da fraqueza da figura paterna - homem alcoolista e violento que levou a família à miséria - a vergonha emerge acompanhada de forte sentimento de culpa.

Em um misto de medo e encantamento, Ivone recorda seu deslumbramento com as luzes da capital:

Cheguei aqui no dia que [nome da cidade] fez 33 anos, eu nunca esqueci, porque no dia que cheguei, a gente que é do interior quando chega na cidade grande, tudo é lindo demais. Tudo é maravilhoso. Nossa, até as luzes das ruas é lindo. Então... Cheguei num dia a noite, no outro dia era aniversario de [cidade], aí passava aqueles mirrage [tipo de avião militar] escrevendo no céu 33, 33, aí eu nunca esqueci né?

Entretanto, a vida na cidade não lhe trouxe uma melhoria em suas condições sociais. Ivone recorda as dificuldades que enfrentou ao precisar trabalhar com serviços domésticos na cidade. Apesar de conhecer muito bem a rotina diária com suas tarefas domésticas na roça, a vida na cidade trouxe desafios que até então não conhecia. O discurso social com o qual se depara na cidade, lhe demonstra seu não-lugar social. A cidade é um ambiente totalmente inóspito a quem não se encaixa. Os indivíduos por falta, usando a expressão de Carreteiro (2003), são colocados à margem e, por não se enquadrarem aos ideais socialmente valorizados, experimentam o silenciamento e a exclusão. Muitas vezes, o discurso hegemônico é tão violento ao ponto do sujeito excluído de fato se identificar com a identidade que lhe é imposta e se conformar com o lugar que lhe é destinado. Ivone relata:
Foi com muita dificuldade, me casei. É... a gente que foi criado lá na roça imaginava assim, que tinha que casar com uma pessoa igual a gente. Até apareceu uma pessoa que poderia ter me dado uma vida melhor, mas eu imaginava assim: 'Não, eu sou muito pobre, tenho que me casar com um igual eu, porque no dia do amanhã ele vai falar pra mim: 'não... quando me casei com você, você não tinha nada, tudo que você tem agradece a mim". Eu achava que aquilo era terrível... e muito mais terrível é você passar dificuldade e vê seus filhos passar dificuldade. Esse que é mais terrivel. Eu passei isso pros meus filhos, mil vezes ter falado, escutado 'não.... quando casei com você, você não tinha nada' do que você escutar seus filhos querendo alguma coisa e você sem condições de comprar.

Gaulejac (2006) ressalta os efeitos da relação estreita entre a objetividade e a subjetividade do sofrimento psíquico-social desencadeado pela pobreza. Existe uma situação concreta resultante da falta de dinheiro - abandono da escola, passar fome, renunciar a outras necessidades para poder comprar comida, mas a recordação e os afetos suscitados são subjetivos e refletem a vivência psíquica do sujeito em sofrimento. Observamos a internalização, por parte de Ivone, do discurso hegemônico sobre o pertencimento social e suas restrições e implicações. Esse discurso reflete a ideia de que existe "um lugar para o pobre", carregado de humilhação. Ivone ressalta o medo de ter que escutar que não merecia ter "uma vida melhor". Esse discurso reverbera a representação da pobreza como um lugar de restrição, de não merecimento de bem-estar social e psíquico. Ao mesmo tempo, percebe a crueldade e crueza de ter que escutar os pedidos de seus filhos sem poder realizá-los. O sofrimento social emerge quando, percebendo-se em um lugar de desvalimento social que acaba por refletir em sua imagem, o sujeito é compelido a assumir a identidade imposta socialmente e que nunca desejou para si.

O projeto identificatório pressupõe um acesso ao registro da temporalidade a partir do qual uma imagem futura do eu se apresentaria ao Eu-atual, afirma Violante (2001). Essa antecipação do eu se apresenta como um projeto a ser construído - o Ideal-de-Eu - como alvo de todas as ações e identificações futuras e anseio que sustenta o percurso do eu, ressalta 
Aulagnier (1990a). Dessa forma, o projeto identificatório é uma "construção de uma imagem ideal que o eu propõe a si mesmo, imagem que poderá aparecer em um espelho futuro, como reflexo daquele que olha" (Aulagnier, 1979, p. 156). Essa construção imaginária, como já discorrido anteriormente, é composta por registros dos ideais tanto parentais quanto sociais. O contrato narcísico é feito entre o sujeito e seu grupo social que pertence a uma sociedade de classes. Para que a criança construa sua autonomia sem perder o suporte identificatório familiar, é fundamental que ela encontre no discurso social referências que lhe permitam se projetar em um futuro passível e possível de investimento, no qual supostamente realizará seu projeto identificatório (Violante, 2001). Ao chegar à cidade, Ivone depara com uma impossibilidade de realização de si mesma, com o esgarçamento do contrato narcísico e é remetida a um lugar de desinvestimento narcísico pelo discurso social. Esse discurso de desvalorização que a anula, desqualifica e desvaloriza, a lança em um lugar de sofrimento e falta de reconhecimento.

Ivone foi, por diversas vezes, 'lembrada' de seu lugar social. Não conseguiu estudar porque precisava encontrar trabalho. Não conseguiu uma ocupação com melhor salário porque não tinha escolaridade suficiente. Não se casou com alguém em melhores condições para não ser humilhada futuramente, mas a humilhação permaneceu quando não conseguiu dar o que os filhos lhe pediam. Aulagnier (1979) enfatiza o peso da realidade histórica principalmente no que tange à "posição de excluído, explorado, de vítima, que a sociedade, efetivamente, impõe ao casal [parental] e à criança" (p. 216). A ruptura do contrato narcísico tem, portanto, consequências diretas sobre o destino psíquico do sujeito.

Ao se casar, identificada com o destino social que lhe foi imputado, Ivone ressalta as dificuldades que enfrentou:

$O$ [filho] mais velho tinha 14 anos, um com 11 eo caçula com 9, [quando] separei do marido. Aí sim [enfatiza] fui trabalhar mesmo [choro]. Você me desculpa. Às vezes é muito ruim lembrar. Muita coisa. Eu sei que... aí criei esses filhos com toda dificuldade, né? [...] Eu não perdia a chance de ganhar um dinheiro, mesmo eu com os meninos pequenos. Os vizinhos precisavam de uma roupa, lavava; outro precisava de passada, eu passava, sabe? Eu fui manicure, costurei, fiz facção [confecção de roupas]. [...] Aífoi mais ou menos na época da separação, que comecei a passar roupa mesmo [muda a entonação de voz em "mesmo" no sentido que precisou aumentar muito a carga de trabalho] pra fora, comecei a trabalhar todos os dias e foi aí que dei conta de criar meus filhos, graças a Deus. Dei muito mais conforto pros meus filhos do que quando eles estavam com o pai, muito mais. Passei muita privação de muita coisa e trabalhando; reformei minha casa, graças a Deus. Hoje minha casa é arrumadinha, tem banheiro, quarto, tudo arrumadinho. Minha casa é forrada, pintadinha, tudo dessas passação de roupa [...]. Até dia de domingo eu trabalhava, sexta-feira da paixão se fosse preciso, natal, ano novo, tudo eu trabalhava, não perdia chance [...]. Eu parei quando eu adoeci, agora, quando eu tive o problema no coração.

Ivone vivencia sua velhice ainda com privações. Ela não conseguiu uma aposentadoria remunerada e recorda que nunca contribuiu com a previdência social porque não podia dispensar o dinheiro que faria falta para a alimentação:

Não tenho aposentadoria porque eu não contribuí com o INSS... Eu não contribuí porque todo mês eu pensava: 'tenho que começar a contribuir, mas esse mês tenho que pagar isso tem aquilo. As necessidades eram grandes $e$ o dinheiro fazia falta, foi desse jeito até passar da hora né?

Apesar de ter conseguido reformar sua casa e deixá-la "arrumadinha", seu relato sobre a vivência da velhice demonstra a discrepância entre o desejado e o real:

a velhice não me traz muita coisa, porque a gente não tem muita condição financeira pra curtir muito a vida. Agora que eu não tô trabalhando, poderia estar passeando muito, poderia estar curtindo melhor a vida. Mas eu sou feliz assim mesmo, muito feliz, graças a Deus".

Essa felicidade soa muito mais como uma racionalização e aceitação de seu lugar social do que uma vivência real de satisfação com a vida. 


\section{Considerações finais}

O poder discursivo e suas reverberações nem sempre são claras, ora se manifestam em normas sociais explícitas, ora implícitas, indicando e coagindo as práticas discursivas dos sujeitos. Certos discursos estão inseridos em ordens discursivas que obscurecem o poder exercido nesse contexto, como observado na narrativa de Ivone. Em casos como esse, algumas operações discursivas se impõem por encontrarem amparo e sustentação ideológica nas práticas sociais do cotidiano.

Chamamos atenção para outro aspecto importante do poder discursivo, discutido por Lima, Lima e Coroa (2016), mas igualmente presente na análise do relato de Ivone. Trata-se do acesso privilegiado que certos grupos sociais têm a recursos, bens, tecnologias e instrumentos simbólicos de circulação discursiva. Dentro dessa perspectiva, cabe ressaltar o pensamento de Van Dijk (2008) que afirma que o "discurso é similar a outros recursos sociais valorizados que constituem a base do poder e cujo acesso é distribuído de forma desigual" (p. 89). Dessa forma, as elites simbólicas retêm certo poder sobre os meios de circulação, difusão e reprodução discursiva, e estabelecem agendas específicas sobre gêneros, estilos e representações discursivas. Como consequência, essas elites encarnam os ideais sociais disponíveis para a identificação do sujeito, e como são socialmente valorizados e desejados, são esses os que irão substituir os ideais parentais.

As práticas discursivas constroem, de tal modo, parâmetros para as identidades, fornecendo aos sujeitos sociais um conjunto de matrizes de significados a partir do qual eles podem se sentir parte de um grupo e desenvolver certas práticas sociais. É nesse sentido que afirmamos que as identidades são construídas discursivamente. Portanto, a escuta clínica do sofrimento psíquico necessita ser também uma escuta do sofrimento social. Explorar coletivamente as histórias de vida em projetos participativos, como as oficinas de revisão de vida desenvolvidas em nosso projeto de extensão, auxiliou no reconhecimento e enfrentamento de experiências silenciadas. $\mathrm{O}$ processo de exclusão social escancara o engodo do pacto social no qual o sujeito é desinvestido e lançado no desamparo. A experiência narrada e a escuta analítica crítica podem se estabelecer como estratégias de resistência ante às situações de humilhação e exclusão social.

A vergonha decorrente desse processo de exclusão se torna, muitas vezes, constituinte da identidade.
Dessa forma, a escuta desse sofrimento não pode estar desligada da compreensão sociopolítica da exclusão social. Além de possibilitar um campo para que o sujeito fale, é necessário que aquele que o escuta, escute a reverberação desse sofrimento em si mesmo. Gaulejac (2006) argumenta que

a capacidade de exprimir a vergonha não depende somente da possibilidade de falar; depende também da necessidade de ser escutado e entendido. E, para aceitar e entender a vergonha do outro, é preciso poder ouvir o eco que ela provoca em si mesmo (p. 98)

Rosa (2012) e Domingues e Rosa (2014) ressaltam que a trajetória habitual do trabalho psicanalítico é o de uma escuta do sujeito que o conduz ao confronto com sua equivocação e que demandará em uma ação coletiva. É no reconhecimento no e pelo outro que também sofre com a humilhação que a ação coletiva se faz possível. Entretanto, Rosa (2012) enfatiza que a ação junto a sujeitos socialmente silenciados necessita conduzir a escuta analítica a novas práticas. A escuta do sofrimento social e psíquico (re)insere a psicanálise no campo das práticas clínico-políticas. Nesse sentido, essa forma de abordagem analítica "dá destaque à alienação do sujeito aos discursos hegemônicos, de modo a visar ao avesso dos mecanismos de individualização, criminalização e patologização por eles produzidos" (Rosa, 2012, p. 31).

Portanto toda escuta necessita ser uma escuta também do sofrimento social inserido em um contexto ideológico-político que impõe silenciamentos e exclusão. A lógica da ética do cuidado necessita oferecer uma espécie de pano de fundo afetivo que legitimem a verdade do sujeito traumatizado e humilhado. É nesse sentido que Alencar (2018), em sua inserção em uma favela, chama a atenção para uma forma de desmentido que opera em contextos de humilhação e sofrimento social. Caberia ao analista, diante desse desmentido social que nega a própria existência do sujeito, auxiliar na construção de um ambiente cuja responsabilidade é facilitar o movimento expansivo do sujeito.

A ação desenvolvida com as mulheres idosas em nosso projeto foi limitada, pois envolvia poucos encontros individuais e grupais com as idosas. Entretanto, trouxe enormes contribuições para pensarmos a escuta analítica como uma ação sociopolítica. Reintegrar o social à compreensão da constituição 
psíquica é fundamental para que a psicanálise possa se reintegrar às discussões ético-políticas, discussões essas necessárias para continuarmos como resistência ante o discurso hegemônico que humilha e exclui os vulneráveis. A ética do cuidado, tão bem desenvolvida por Penna (2017), convoca a presença e a escuta cuidadosa do analista no combate contra a alienação e miséria, de si mesmo e do outro vulnerável.

\section{Referências}

Alencar, S. (2018). São 788 degraus: a psicanálise sobe o morro. Cadernos de Psicanálise, 40(38), 59-76.

Aulagnier, P. (1979). A violência da interpretação: do pictograma ao enunciado. (M. C. Pellegrino, Trad.). Rio de Janeiro, RJ: Imago.

Aulagnier, P. (1989). O aprendiz de historiador e o mestre-feiticeiro: do discurso identificante ao discurso delirante (C. Berlinger, Trad.). São Paulo, SP: Escuta.

Aulagnier, P. (1990a). Um intérprete em busca de sentido (R. Steffen, Trad., Vol. 1). São Paulo, SP: Escuta.

Aulagnier, P. (1990b). Um intérprete em busca de sentido (R. Steffen, Trad., Vol. 2). São Paulo, SP: Escuta.

Aulagnier, P. (1999). Nascimento de um corpo, nascimento de uma história (V. Conrad, Trad.). Revista Latinoamericana de Psicopatologia Fundamental, 2(3), 9-45.

Bertaux, D. (2010). Narrativas de vida: a pesquisa e seus métodos Natal, RN: EDUFRN. (Trabalho original publicado em 2005)

Carreteiro, T. (2003). Sofrimentos sociais em debate. Psicologia USP, 14(3), 57-72.

Castel, R., \& Haroche, C. (2001). Propriété privée, propriété sociale, propriété de soi. Paris: Fayard.

Davis, A. (2016). Mulheres, raça e classe (H. R. Candiani, Trad.). São Paulo, SP: Boitempo. (Trabalho original publicado em 1981)

Domingues, E., \& Rosa, M. (2014). Violência, humilhação social e a luta por reconhecimento: a experiência do MST. Subjetividades, 14(1), 115-125.

Fanon, F. (1952). Pele negra, máscaras brancas (R. Silveira, Trad.). Salvador, BA: Edufba.

Flick, U. (2009). Introdução à pesquisa qualitativa (J. E. Costa, Trad., 3a ed.). Porto Alegre, RS: Artmed. (Trabalho original publicado em 1995)

Foucault, M. (1988). História da sexualidade: a vontade de saber (M. Albuquerque, Trad., 13a ed.). Rio de Janeiro, RJ: Edições Graal. (Trabalho original publicado em 1976)

Freud, S. (2010). Introdução ao narcisismo. In Obras completas: Introdução ao narcisismo, Ensaios de metapsicologia e outros textos (P. C. Souza, Trad., Vol. 12, pp. 13-50). São Paulo, SP: Companhia das Letras. (Trabalho original publicado em 1914)

Freud, S. (2010). O mal-estar na civilização. In Obras completas: O mal-estar na civilização e outros textos (P. C. Souza, Trad., Vol. 18, pp. 13-122). São Paulo, SP: Companhia das Letras. (Trabalho original publicado em 1930)

Freud, S. (2010). Tipos de adoecimento neurótico. In Obras completas: Observações psicanalíticas sobre um caso de paranoia relatado em autobiografia ("O caso Schreber"), artigos sobre técnica e outros textos (P. C. Souza, Trad., Vol. 10, pp. 229-239). São Paulo: Companhia das Letras. (Trabalho original publicado em 1912)

Gaulejac, V. (2006). As origens da vergonha (M. B. Medina, Trad.). São Paulo, SP: Via Lettera.

Gaulejac, V. (2014). Neurose de classe (M. B. Medina \& N. Takeuti, Trad.). São Paulo, SP: Via Lettera.

Gonçalves Filho, J. M. (1998). Humilhação social: um problema político em Psicologia. Psicologia USP, 9(2), 11-67.

Jovchelovitch, S., \& Bauer, M. (2002). Entrevista narrativa. In M. Bauer \& G. Gaskell (Eds.), Pesquisa qualitativa com texto, imagem e som: um manual prático (P. A. Guareschi, Trad., pp. 90-113). Petrópolis, RJ: Vozes.

Lima, S., Lima, P., \& Coroa, M. L. (2016). Identidade de velhos: modos de identificação e discursos de resistência na velhice. Domínios de Lingu@Gem, 10(3), 903-926. 
Musatti-Braga, A. (2015). Os muitos nomes de Silvana: contribuições clínico-políticas da psicanálise sobre mulheres negras. Tese de doutorado (Programa de Pós-graduação em Psicologia). Instituto de Psicologia. Universidade de São Paulo, SP.

Musatti-Braga, A., \& Rosa, M. (2018). Escutando os subterrâneos da cultura: racismo e suspeição em uma comunidade escolar. Psicologia em Estudo, 23, e2315.

Penna, C. (2017). O campo dos afetos: fontes de sofrimento, fontes de reconhecimento. Dimensões pessoais e coletivas. Cadernos de Psicanálise, 39(37), 11-27.

Rosa, M., \& Mountian, I. (2013). Psychoanalytic listening to socially excluded young people. Psychoanalysis, Culture \& Society, 18(1), 1-16.

Rosa, M. (2002). Uma escuta psicanalítica das vidas secas. Revista Textura, 2(2), 42-47.

Rosa, M. (2012). Psicanálise implicada: vicissitudes das práticas clinicopolíticas. Revista da Associação Psicanalítica de Porto Alegre, 41-42, 29-40.

Sequeira, V. (2009). Pedro e o lobo: o criminoso perverso e a perversão social. Psicologia: Teoria e Pesquisa, $25(2), 221-228$.

Souza, N. S. (1983). Tornar-se negro. Rio de Janeiro, RJ: Edições Graal.

Van Dijk, T. A. (2008). Discurso e poder. São Paulo, SP: Contexto.

Violante, M. (2000). A perversidade da exclusão social. In D. Levisky (Org.), Adolescência e violência: consequências da realidade brasileira (pp. 63-75). São Paulo, SP: Casa do Psicólogo.

Violante, M. (2001). Piera Aulagnier: uma contribuição à obra de Freud. São Paulo, SP: Via Lettera.

\section{Priscilla Melo Ribeiro de Lima}

Professora do curso de Psicologia e docente do Programa de Pós-Graduação em Psicologia (PPGP) da Faculdade de Educação da Universidade Federal de Goiás, Goiás - GO. Brasil.

E-mail: primlima@ufg.br

(D) https://orcid.org/0000-0003-2426-0715

\section{Sostenes Cezar de Lima}

Professor do curso de Letras e do Programa de Pós-graduação Interdisciplinar em Educação, Linguagem e Tecnologias (PPG-IELT) da Universidade Estadual de Goiás, Unidade Universitária Anápolis de Ciências Socioeconômicas e Humanas, Goiás - GO. Brasil.

E-mail: limasostenes@gmail.com

(D) https://orcid.org/0000-0002-1814-3996

Endereço para envio de correspondência:

Universidade Federal de Goiás, Faculdade de Educação. Rua 235, Setor Universitário. CEP: 74605-050. Goiânia GO. Brasil.

Recebido 16/01/2018

Aceito 18/02/2019

Received 16/01/2018

Approved 18/02/2019

Recibido 16/01/2018

Aceptado 18/02/2019 
Como citar: Lima, P. M. R., \& Lima, S. C. (2020). Psicanálise Crítica: A Escuta do Sofrimento Psíquico e suas Implicações Sociopolíticas. Psicologia: Ciência e Profissão, 40, 1-15. https://doi.org/10.1590/1982-3703003190256

How to cite: Lima, P. M. R., \& Lima, S. C. (2020). Critical Psychoanalysis: Psychic Suffering Listening and its SocioPolitical Implications. Psicologia: Ciência e Profissão, 40, 1-15. https:// doi.org/10.1590/1982-3703003190256

Cómo citar: Lima, P. M. R., \& Lima, S. C. (2020). Psicoanálisis Crítica: la Escucha del Sufrimiento Psíquico y sus Implicaciones Socio-Políticas. Psicologia: Ciência e Profissão, 40, 1-15. https://doi.org/10.1590/1982-3703003190256 